\title{
EDUCAÇÃO E LINGUAGEM NA SOCIEDADE DIGITAL: CRÍTICA E CONSTRUÇÃO DE SENTIDOS
}

\author{
EDUCATION AND LANGUAGE IN THE DIGITAL SOCIETY: CRITIQUE AND MEANING MAKING
}

\author{
Adriana Lúcia de Escobar Chaves de Barros ${ }^{1}$, Marcia Lisbôa Costa de Oliveira ${ }^{2}$, Ricardo \\ Toshihito Saito ${ }^{3}$, Sandra Regina Buttros Gattolin ${ }^{4}$ \\ ${ }^{1}$ Universidade Estadual de Mato Grosso do Sul (UEMS), Campo Grande, MS, Brasil \\ chaves.adri@hotmail.com \\ 2 Universidade do Estado do Rio de Janeiro (UERJ), Rio de Janeiro, RJ, Brasil \\ lisboamarcia@hotmail.com \\ ${ }^{3}$ Universidade Federal da Bahia (UFBA), Salvador, BA, Brasil \\ ricardosaito@yahoo.com \\ 4 Universidade Federal de São Carlos (UFSCar), São Carlos, SP, Brasil \\ sandragattolin@gmail.com
}

À chamada pública para artigos deste dossiê, divulgada em setembro de 2018, responderam pesquisadores ligados por múltiplos laços ao trabalho da Professora Doutora Walkyria Maria Monte Mór, Livre-Docente da Universidade de São Paulo, pesquisadora adjunta do Center for Globalization and Cultural Studies da Universidade de Manitoba - Canadá, onde realizou sua pesquisa de pós-doutorado (2007). Assim, o dossiê temático que apresentamos no número 15 da Pensares em Revista homenageia a professora Walkyria, coordenadora, junto ao Professor Doutor Lynn Mario T. Menezes de Souza (DLM-USP), do Projeto Nacional de Letramentos: Linguagem, Cultura, Educação e Tecnologia, que, desde 2015, vem reunindo pesquisadores, a fim de estudar e refletir sobre as condições atuais do ensino de línguas no Brasil e pensar em propostas de renovação.

Nossa homenageada vem se dedicando às questões sobre o ensino de línguas há bastante tempo. Além de ter co-coordenado o Projeto Nacional de Formação de Professores "Novos letramentos, multiletramentos e línguas estrangeiras", cadastrado no Diretório dos Grupos de Pesquisa do CNPq, de 2009 a 2015, Walkyria Monte Mór é co-autora das Orientações Curriculares Nacionais para o Ensino Médio: Línguas Estrangeiras (MEC/2006) e autora dos Cadernos de Orientações Didáticas para EJA-Línguas Estrangeiras (Secretaria Municipal de Educação de São Paulo/2010). 
Suas pesquisas recentes concentram-se em Linguagem e Educação, Letramentos (Novos Letramentos, Multiletramentos, Letramentos Críticos), Construção de Sentidos e Formação de Professores. Daí o título deste dossiê Educação e linguagem na sociedade digital: crítica e construção de sentidos - que reúne pesquisas no campo da Linguística Aplicada, desenvolvidas, em sua maioria, pelos participantes do Projeto Nacional de Letramentos: Linguagem, Cultura, Educação e Tecnologia, do qual também fazem parte os organizadores desta edição da Pensares em Revista.

Para além da importância de seu trabalho acadêmico, Walkyria é uma pessoa que seus orientandos e amigos espalhados pelo Brasil e pelo mundo definem pelo substantivo generosidade. Esse traço se expressa tanto em pequenos gestos cotidianos de cuidado, quanto nos temas que investiga, sempre atravessados por um profundo respeito ao Outro.

Por tudo isso, é com alegria que oferecemos aos leitores este dossiê, que apresenta oito artigos e três entrevistas. Os artigos estão organizados em três eixos: Formação de Professores, Letramentos e Sociedade; Criação e (co)construção do conhecimento no Ensino-Aprendizagem de Línguas; Letramentos Críticos e o Ensino de Línguas.

Iniciando o primeiro eixo, Formação de Professores, Letramentos e Sociedade, Brian Morgan, Ian Martin e Ruberval Maciel, em The Walkyria Effect: Inspiring Transnational Language Teacher Education fogem ao formato convencional da escrita acadêmica para celebrarem o "Efeito Walkyria". Lançando mão de uma abordagem de pesquisa duoetnográfica (Norris \& Sawyer, 2012; Breault, 2016), os três autores dialogam sobre as contribuições acadêmicas e interpessoais de Monte Mór para sua compreensão emergente da formação de professores de línguas transnacionais, a partir do conceito de subjetificação.

Na sequência, Nara Hiroko Takaki, Daniel de Mello Ferraz e Souzana Mizan apresentam Repensando a Educação Linguística com Contribuições de Ricoeur, em que exploram alguns conceitos da filosofia ricoeuriana, que está fortemente marcada nas pesquisas de Walkyria (MONTE MÓR, 1999; 2018). A partir de um olhar hermenêutico, pensam sobre interpretação, formação de professores de 
línguas/linguagens, letramentos e sociedade e educação linguística, oferecendo orientações pedagógicas de base filosófica.

A seguir, em Refletindo sobre as experiências do curso "Formação Continuada de Professores de Inglês como Língua Adicional", Ana Karina de Oliveira Nascimento, Marlene de Almeida Augusto de Souza e Vanderlei José Zacchi refletem sobre a formação continuada de professores de línguas em uma perspectiva crítica, a partir da análise de relatos das experiências de participantes de um projeto de extensão desenvolvido em 2017 por integrantes do grupo de pesquisa Letramentos em inglês: língua, literatura e cultura (Linc) da Universidade Federal de Sergipe, que ofereceu cursos para professores de inglês da educação básica.

Encerrando esta seção, no artigo Formação Crítica de Professores: por um ensino de línguas socialmente responsável, Andrea Machado de Almeida Mattos, Leina Jucá e Míriam Lúcia dos Santos Jorge discutem pesquisas e práticas desenvolvidas por integrantes do Núcleo Parceiro de Belo Horizonte e Região, filiado ao Projeto Nacional de Formação de Professores nas Teorias dos Novos Letramentos e Multiletramentos. Assim, abordam propostas relacionadas à formação inicial de professores, à formação continuada e ao ensino de línguas na perspectiva da educação para as relações étnico-raciais.

O segundo eixo, que tem como tema Criação e (co)construção do conhecimento no Ensino-Aprendizagem de Línguas, apresenta dois artigos. No primeiro, Em busca de novos designs pedagógicos: etnografia e a co-construção de redes de conhecimento em um curso de formação de professores de língua inglesa, Ricardo Toshihito Saito, situando-se como um professor outsider, desenvolve uma abordagem etnográfica de seu papel como formador de professores de língua inglesa em uma universidade pública, enfocando o trabalho desenvolvido na disciplina estágio supervisionado. Sua abordagem busca a horizontalização das relações entre professor universitário, estagiários e professores da escola básica e aponta para uma atuação mais crítica e situada que tome em consideração as várias redes e espirais de conhecimento em co-construção com o outro que permeiam a formação de professores.

No artigo "Eles començam sanguear": translinguagem como prática criativa e de construção de conhecimento em português língua estrangeira, Giovana Nicolini 
Milozo e Sandra Regina Buttros Gattolin partem do pressuposto de que "a comunicação transcende as línguas individuais e as "fronteiras" estabelecidas entre elas, de modo a corresponder aos interesses e necessidades de sujeitos e de comunidades" para analisar a prática comunicativa de um aprendiz italiano, num curso de português oferecido por uma universidade pública do estado de São Paulo. As autoras defendem que, na sala de aula de línguas, o preconceito em relação à "mistura" de línguas deve dar lugar à valorização do repertório linguístico trazido por alunos estrangeiros.

Abrindo o terceiro e último eixo, intitulado Letramentos Críticos e o Ensino de Línguas, Luana Cristina Amorim Roja de Lima e Adriana Lúcia de Escobar Chaves de Barros, em Goldilocks and the three bears: práticas e reflexões sobre momentos de criticidade emergentes da leitura de uma estória infantil, trazem o recorte de uma pesquisa qualitativa interpretativa com característica etnográfica que se deu em uma turma do $3^{\circ}$ ano do Ensino Fundamental de uma escola pública de Terenos - MS. A investigação apresentada busca verificar em que medida a leitura e as atividades relacionadas à narrativa Goldilocks and the three bears podem contribuir para a emergência de momentos de criticidade em uma aula de Língua Inglesa para crianças.

No artigo seguinte, Katia Bruginski Mulik e Elaine Íris dos Reis apresentam Letramento crítico, ensino de línguas estrangeiras e questões filosóficas: diálogos com Bourdieu e Derrida, em que abordam a noção de letramento como proposta educacional, tendo em vista as mudanças ocasionadas pela globalização nas relações culturais, econômicas, sociais e tecnológicas. Segundo as autoras, pela perspectiva dos Letramentos Críticos, o ensino de línguas estrangeiras implica em um trabalho pedagógico voltado para práticas de leituras de mundo e de diferentes discursos de forma aprofundada, levando em conta o papel ativo do leitor na construção desses sentidos dentro e fora da escola, a fim de buscar a formação crítica dos alunos.

As entrevistas enfeixadas nesse dossiê tematizam preocupações importantes na obra de Walkyria Monte Mór, a partir de diferentes angulações. Na entrevista intitulada Parceria acadêmica e esperança equilibrista: uma conversa com Lynn Mario Trindade Menezes de Souza, os organizadores tiveram o privilégio de 
conversar com o professor Lynn Mario, importante parceiro acadêmico de Walkyria Monte Mór, sobre o modo como ele pensa o contexto contemporâneo, provocando-o a refletir sobre conceitos como colaboração acadêmica, produção de saberes, injustiça e desigualdade, lugar de fala/posição enunciativa, epistemologias da experiência, decolonialidade e esperança. A entrevista/conversa é atravessada por uma profunda reflexão sobre a obra Paulo Freire e as dimensões que suas concepções assumem na atualidade.

Em Reimagining neoliberalism, globalization, literature and language education: an interview with prof. Dr. Diana Brydon, Daniel de Mello Ferraz entrevistou a professora da University of Manitoba (Winnipeg - MB - Canadá), problematizando concepções sobre globalização, neoliberalismo, literatura e educação linguística, dentro e fora de contextos e fronteiras transnacionais. Com relação ao termo neoliberalismo, por exemplo, Brydon discute o esvaziamento semântico que contribui para o silenciamento acerca de suas implicações na produção de desigualdades e de privação de direitos.

Fechando o dossiê, apresentamos a entrevista O Pensamento "Fraco" e a Esquerda Brasileira: Entrevista com o filósofo italiano Gianni Vattimo, realizada por Andréa Cotrim Silva, Khalid Tailche e Francesca Dell'Olio. Na entrevista, o filósofo italiano, que exerce intensa atividade político-reflexiva, fala sobre a política brasileira das últimas décadas, reflete e aponta novos caminhos, retoma ideias apresentadas em seu livro "Hermeneutic Communism" e discute participação política, democracia "fraca" e a formação do cidadão crítico. Vattimo alude ao slogan da "Campanha das Cem Flores", desencadeada pelo Partido Comunista Chinês em 1956 - "Que flores de todos os tipos desabrochem, que diversas escolas de pensamento se enfrentem!"1 - para falar de contradições entre criação e controle, criatividade e propriedade, no interior dos sistemas. O filósofo fala da necessidade de "fazer bagunça", e da desordem/importunação como estratégia de multiplicação de centros de resistência ao poder, e nos instiga a fazer, cada qual, um pouco mais de bagunça contra-hegemônica.

\footnotetext{
${ }_{1}^{1}$ http://manifestodavontade.blogspot.com/2007/10/desabrochar-de-cem-flores.html
} 
Esperamos que este número da Pensares em Revista fomente diálogos e estudos sobre Linguagem e Educação, Novos Letramentos, Multiletramentos, Crítica e Construção de Sentidos, Pedagogia Crítica, Formação de Professores, provoque desordens no pensamento estabelecido, amplie os debates a partir das reflexões propostas nestas fontes plurais e propicie discussões produtivas no campo da Linguística Aplicada e de suas relações com as demais áreas, inspiradas nas ideias de Walkyria Monte Mór.

Os organizadores

\section{Sobre os organizadores}

\section{Adriana Lúcia de Escobar Chaves de Barros}

Possui pós-Doutorado em Letras Modernas pela USP (2016-2017). É Doutora em Estudos da Linguagem pela PUC-Rio (2010). Mestre em Administração de Empresas com especialização em Marketing pelo IAG Escola de Negócios da PUC-Rio (2006). Diplomada no curso de pós-graduação em Management (MBA) pelo IAG Escola de Negócios da PUC-Rio (2003). Diplomada no curso de pós-graduação em Metodologia do Ensino da Língua Inglesa (DOTE - Diploma for Overseas Teachers of English, RSA) pela Universidade de Cambridge, Inglaterra (1994), adquirindo o título de Royal Society of Arts. Graduada em Letras Português-Inglês Licenciatura Plena pela PUC-Rio (1984). Atualmente é professora efetiva da Universidade Estadual do Mato Grosso do Sul, ministrando aulas nos cursos de graduação e de pós-graduação stricto sensu do Mestrado Acadêmico e Profissional em Letras. Atualmente, suas áreas de interesse são: Sociolinguística Interacional/Variacionista e Linguística Aplicada, com foco em Ensino de Línguas, Formação de Professores, Línguas de Comunidades Minoritárias e (De)colonialidade, Fronteiras, Língua, Cultura e Identidade.

\section{Marcia Lisbôa Costa de Oliveira}

Doutora em Letras (FL - UFRJ, 2002) com Pós-Doutorado em Letras Modernas (FFLCH-USP, 2017). Atua como Professora Adjunta da Universidade do Estado do Rio de Janeiro e membro do corpo docente do Mestrado Profissional em Letras e do Programa de Pós-graduação em Letras e Linguística da FFP/UERJ. É membro do Grupo de Pesquisa Linguagem \& Sociedade (FFP/UERJCNPq) e líder do Grupo de Pesquisa UERJ/SECMS/CIEP250 Conversa de professor: construindo relações entre teoria e metodologia numa comunidade de prática. Pesquisa principalmente os seguintes temas: teorias da leitura, letramentos numa perspectiva sociocultural, formação de professores e desigualdades sociais. 


\section{Ricardo Toshihito Saito}

É professor em contínua formação na Universidade Federal da Bahia, investiga questões relacionadas à Formação de Professores, Letramentos e Tecnologias com suas alunas e alunos do curso de Licenciatura em Letras e professoras da rede pública de ensino da cidade de Salvador/BA. Bacharel em Linguística, Licenciado em Pedagogia e Letras e Mestre em Letras, é atualmente doutorando do Programa de Pós-graduação em Estudos Linguísticos e Literários em Inglês na Universidade de São Paulo, cuja pesquisa contempla a co-construção de redes de conhecimento e designs pedagógicos outros em cursos de formação continuada de professores de línguas, letramentos e tecnologias.

\section{Sandra Regina Buttros Gattolin}

Concluiu Pós-Doutorado no departamento de Letras Modernas da Faculdade de Filosofia, Letras e Ciências Humanas (FFLCH/USP), é Doutora e Mestre em Linguística Aplicada pela Universidade Estadual de Campinas, instituição em que iniciou sua pesquisa na área de ensino-aprendizagemavaliação de segunda língua e língua estrangeira. Atualmente é professora associada do Departamento de Letras da Universidade Federal de São Carlos, onde também atua no Programa de Pós-Graduação em Linguística. Foi presidente da Associação dos Professores de Língua Inglesa do Estado de São Paulo nos períodos de 2005 a 2007 e 2009 a 2011. Suas áreas de interesse em pesquisa são o ensino-aprendizagem-avaliação de língua estrangeira, a formação de professores de língua estrangeira e os novos letramentos, multiletramentos e letramento crítico. 